\title{
Failure Study of Two Dissimilar Steels Joined by Spot Welding Technique ALI Dad Chandio ${ }^{a^{*}}$, NABEEL A. Khan ${ }^{\mathrm{b}}$, RAMEEZ Jawaid ${ }^{\mathrm{C}}$ and S. NAQI Mohsin ${ }^{\mathrm{d}}$
}

\author{
Department of Materials and Metallurgical Engineering, NED University of Engineering and \\ Technology, Karachi 75270 Pakistan \\ ”aalidad_24@hotmail.com, 'bnabeel.ahmed27@hotmail.com, 'rameez.jawaid07@gmail.com, \\ dnaqi.mohsin123@gmail.com
}

\begin{abstract}
Keywords: Resistance spot welding, Failure mode, Pull-out mode, Interfacial mode, FZS
\end{abstract}
\begin{abstract}
The resistance spot welding process is of paramount importance in the automotive industry for the fabrication of metallic components. Several dissimilar alloys could easily be joined by resistance spot welding. However, the joining of the stainless steel and galvanized carbon steel is challenging task since weld fusion zone properties are affected significantly. Indeed, the reliability of the component lies in the sound quality of spot weld. The overload failure mode of the weld zone was determined by preparing lap-shear specimens and then carrying out tensile-shear test. Microstructures and hardness of the weld nuggets were also brought under considerations. It was found that weld nugget size and strength of that sheet material which had lower electrical resistance were the controlling factors of the failure mode. The aim of this study was to find out the causes of spot weld failure in terms of parameters favoring the pullout failure mode, role of fusion zone size, nugget and base metal by controlling the process parameters.
\end{abstract}

\section{Introduction}

The biggest challenge nowadays for vehicle manufacturers is to cope themselves up to become answerable to the aspirations of the customers and to prepare themselves for the worldwide competition. These challenges include: resistance from corrosion, high strength of sheets, the ability of the weld joint to withstand external forces and impacts, and cost-efficiency. Several research have been carried out to inquire the above-mentioned requirements [1]. Automotive industry terms resistance spot welding as the most leading and dominant process for the joining of thin metal sheet parts. Characteristically, the structure of a modern vehicle is made up using resistance spot welding technique. The main benefits for which resistance spot welding is preferred over other welding techniques is its easiness, lesser in cost, high speed (which leads to decrease the processing time) and mechanisation [2]. Keeping in mind, the increased usage of stainless steel in automotive (rail), cars and buses and the use of low carbon steels in these applications, employment of resistance spot welding of dissimilar steel sheets in modern vehicle design has become a practical requirement which is unavoidable. The varying thickness of both metal sheets is very common in automotive industry. The thickness is determined by the function of the sheet and the design concept [3]. The outmost possibility of manufacturing even one or two flawed spot welds in an important part wants to be excluded to confirm and sustain the structural reliability of a manufactured part in different functioning environments. Since it is very difficult to employ NDT to spot welds, the need urges to produce good spot welds along with some other uncertainties that are accountable for making more spot welds then the actual requirement which are essential for maintaining structural reliability of the vehicle. A modern vehicle contains about 3000-5000 spot welds, around $30 \%$ of these are because of the uncertainty associated with the quality and reliability of the spot welds. Due to making more spot welds than required, major increase in cost is inevitable. This leads to the need of optimizing this process[4]. Generally, there are two modes in which a failure can occur in resistance spot welding: Interfacial mode and nugget pull out mode. A crack propagates and causes the spot weld to fail in interfacial mode. The weld nugget broke into two pieces in interfacial mode, whereas 
in pull out mode, the whole spot weld (or sometimes partial) is removed from the sheet. These failure behaviours determine the quality of the spot weld. Load carrying capacity largely depends upon these failure behaviours of the spot welds [5].

Regardless of numerous applications of dissimilar resistance spot welding, very limited research reports are available which leads to this research in which the failure behaviour of spot welds of dissimilar welding and the factors associated with its failure are going to be investigated.

\section{Experimental Approach}

Materials. In this study, the materials being used along with their chemical composition that was analysed using optical emission spectroscopy (OES) that are shown in Table 1.

Table 1. Wt.\% composition of both steel sheets.

\begin{tabular}{|c|c|c|c|c|c|c|c|c|c|c|c|}
\hline Elements & $\bar{C}$ & $\mathrm{Cr}$ & $\mathbf{N i}$ & $\mathbf{S i}$ & Mn & $\mathbf{S}$ & $\mathbf{N b}$ & Mo & $\mathbf{C u}$ & $\overline{\mathbf{P}}$ & $\mathbf{F e}$ \\
\hline $\begin{array}{l}\text { Stainless } \\
\text { Steel } \\
\text { (AISI 304) } \\
\text { Carbon }\end{array}$ & 0.049 & 8.3 & 5.5 & 0.28 & 1.42 & 0.01 & 0.08 & 0.07 & 0.08 & 0.03 & Bal \\
\hline $\begin{array}{l}\text { Steel (AISI } \\
1020 \text { ) }\end{array}$ & 0.058 & 0.05 & 0.07 & 0.08 & 0.20 & 0.012 & - & - & 0.03 & 0.016 & $\mathrm{Bal}$ \\
\hline
\end{tabular}

Methods. Resistance spot welding was carried out by making use of a $150 \mathrm{kVA}$ AC pedestal type resistance spot welding (RSW) machine (Panasonic YF-020125). Welding was conducted using a RWMA class 2 copper electrode with $6 \mathrm{~mm}$ face diameter. During welding, all the parameters except welding current were kept constant as shown in Fig. 1. A constant force was supplied while the pressure was supplied externally.

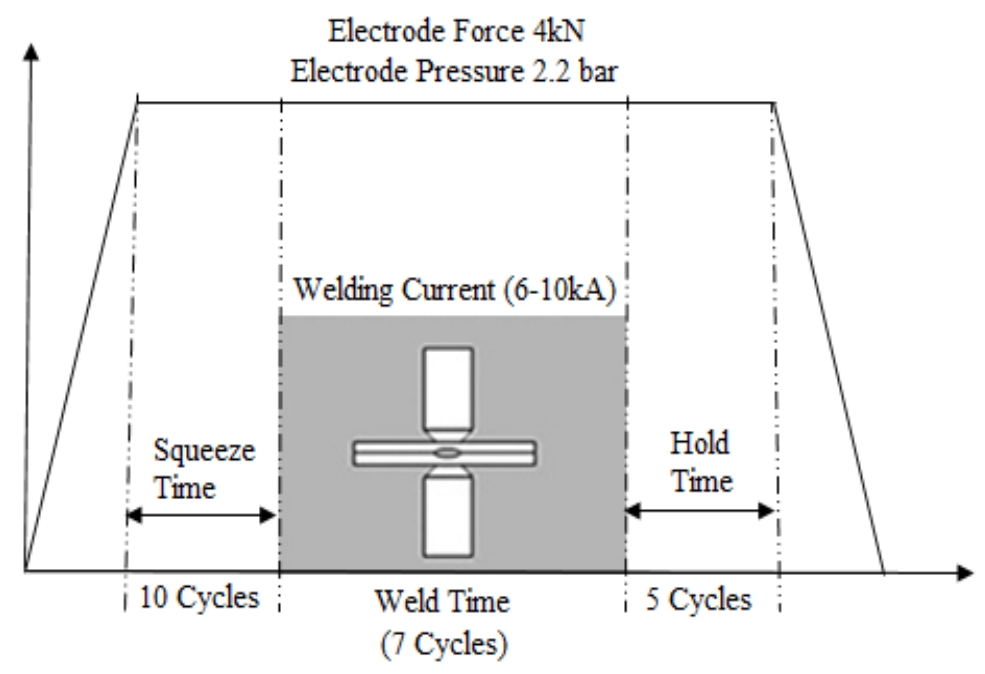

Fig. 1. Welding parameters used in this investigation.

In addition, the dimensions of the specimen are shown in Fig. 2. The standard ANSI/AWS/SAE/D8.9-97 was employed when preparing the samples for static tensile-shear test.

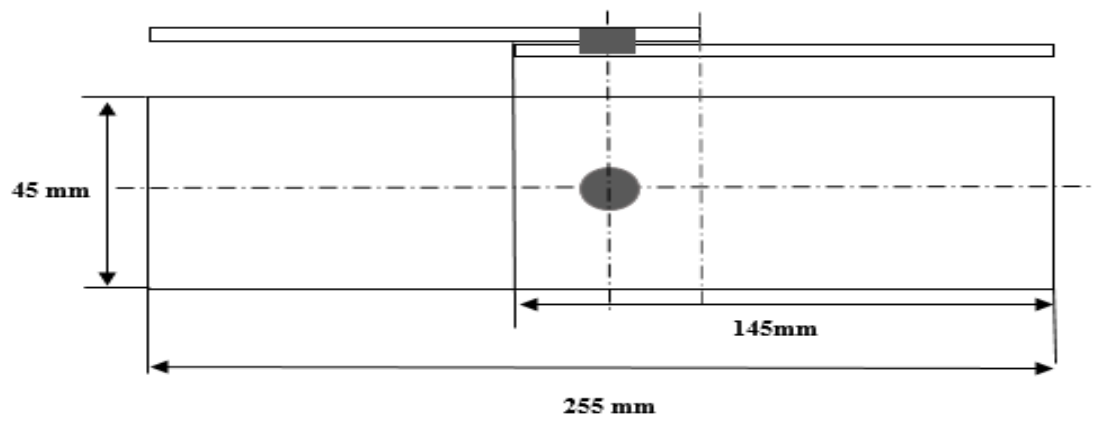

Fig. 2. Dimension of the tensile-shear specimen. 
Testing and Characterisation. A Daekyung $(600 \mathrm{kN})$ Universal Testing Machine was used for tensile-shear test. Yield and Peak load were obtained from the load-displacement curve. Failed samples were check to determine the failure behaviour [3]. Stereo microscope (Model: ZMKZ03) was used to calculate the fusion zone size (FZS) of both the steel at 10x magnification. Hardness of the weld nuggets were calculated by using a Shimadzu micro-vicker hardness tester. The load used in hardness testing was $100 \mathrm{~g}$. The indent was made, by using a diamond intender, 50 micro metre away from the weld centreline for the galvanized and stainless steels [6].

\section{Results \& Discussion}

Fusion Zone Size (FZS). An asymmetrical shape of the weld nugget was obtained because of dissimilar resistance spot welding which evidently differentiating the thermal and electrical efficiencies of both steel sheets as shown in Fig. 3. The abbreviation FZ, SS and GS in Fig. 3 are fusion zone, stainless steel and galvanised steel, respectively.

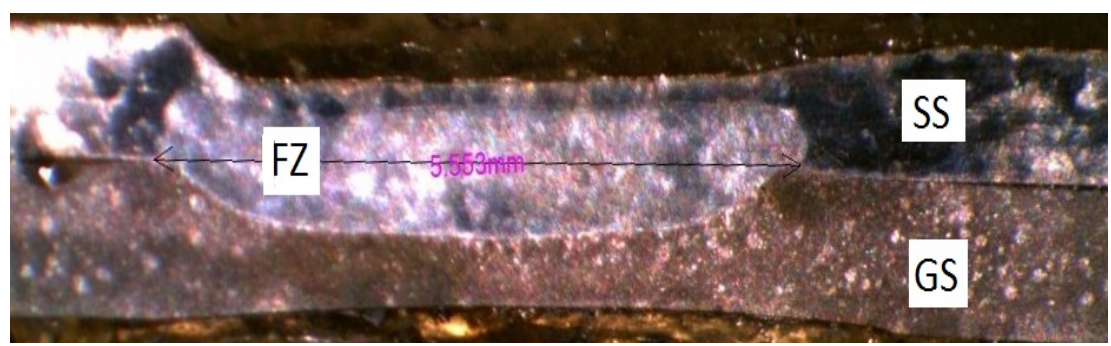

Fig. 3. Asymmetrical shape of weld nugget (magnification 10x).

The FZS of stainless steel was larger as compared to the FZS of galvanised steel due to differences in the value of thermal conductivity. Higher thermal conductivity of low carbon steel led to smaller FZS of galvanised steel side. FZS of both steel sides increased with increased welding current as shown in Fig. 4. [7].

Hardness of the Weld Nugget. The hardness of galvanised carbon steel and stainless steel were $118 \mathrm{HV}$ and $207 \mathrm{HV}$, respectively. The hardness of the weld nugget at $\mathrm{Iw} \geq 8 \mathrm{kA}$ was found much higher than stainless steel and galvanised steel as shown in Fig. 5. The hardness of the weld nugget at $\mathrm{Iw}=8 \mathrm{kA}$ was 3.3 times greater than the hardness of galvanised carbon steel and 1.90 times greater than the hardness of stainless steel. This drastic increase in the hardness value indicates the formation of martensite in this region as resistance spot welding is termed as one of the most rapid cooling welding process or it could be due to presence of residual stresses.

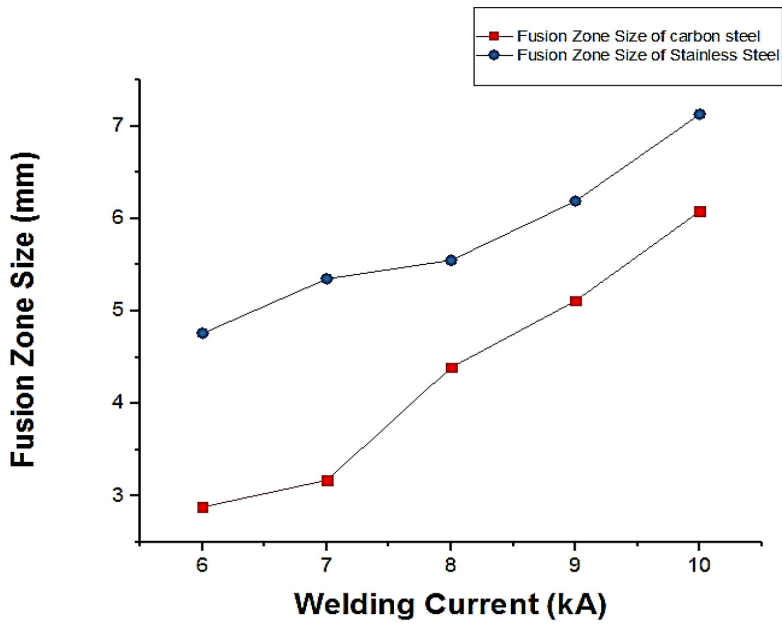

Fig. 4. Welding current affecting the FZS of both steel.

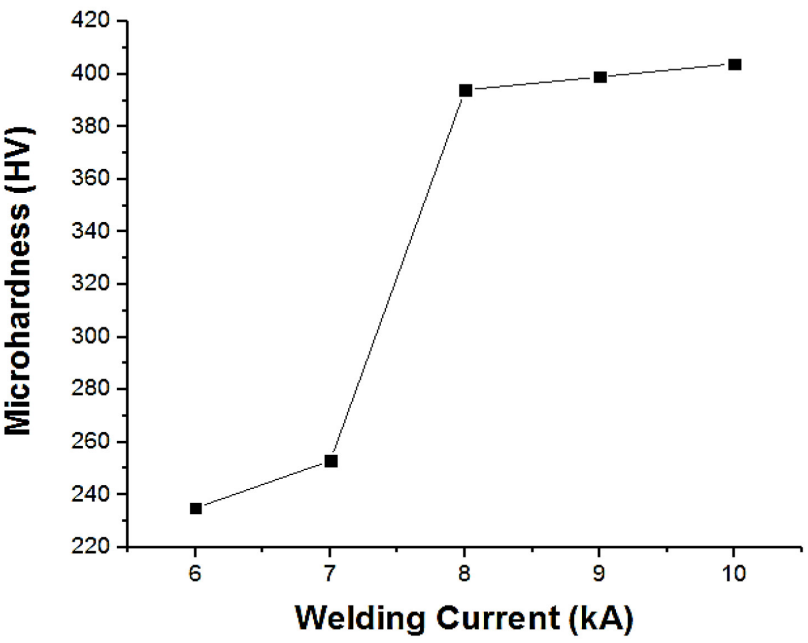

Fig. 5. Hardness of the weld nugget at varying welding current.

Microstructure. The formation of martensite in the weld nugget was confirmed by using Schaeffler diagram. The \%dilution (carbon steel to stainless steel volume ratio in the weld nugget) is given in Table 2. 
At $I w \leq 7 \mathrm{kA}$, Schaeffler diagram predicts a microstructure of Ferrite+Martensite. However, at $I w \geq 8 \mathrm{kA}$, presence of martensite is confirmed as shown in Fig. 6. Despite the low carbon content of both the steels, formation of martensite is a result of high cooling rate of resistance spot welding. The dependence of weld nugget hardness gets weaker with increasing current as no change is shown by changing the predicted microstructure between $45-70 \%$ dilution [3].

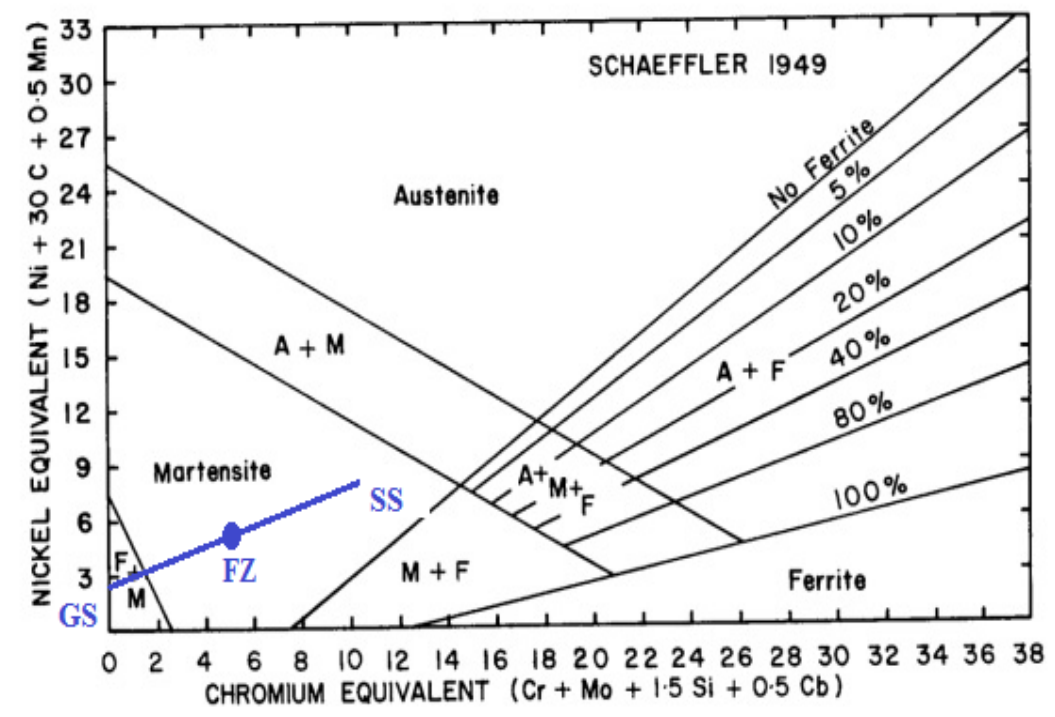

Fig. 6. Prediction of microstructure of the spot weld using Schaeffler diagram at dilution $49 \%$ [3].

Failure Analysis. The results of static tensile-shear test indicating failure of the sample in two distinctive modes i.e., interfacial fracture (IF) and nugget pull-out (PF) (Fig. 7). It is quite evident from the experimental outcome that the two most significant parameters in resistance spot welding are the welding current and FZS. Welding current (which leads to increase in FZS) significantly affects the mode by which the spot weld fails.

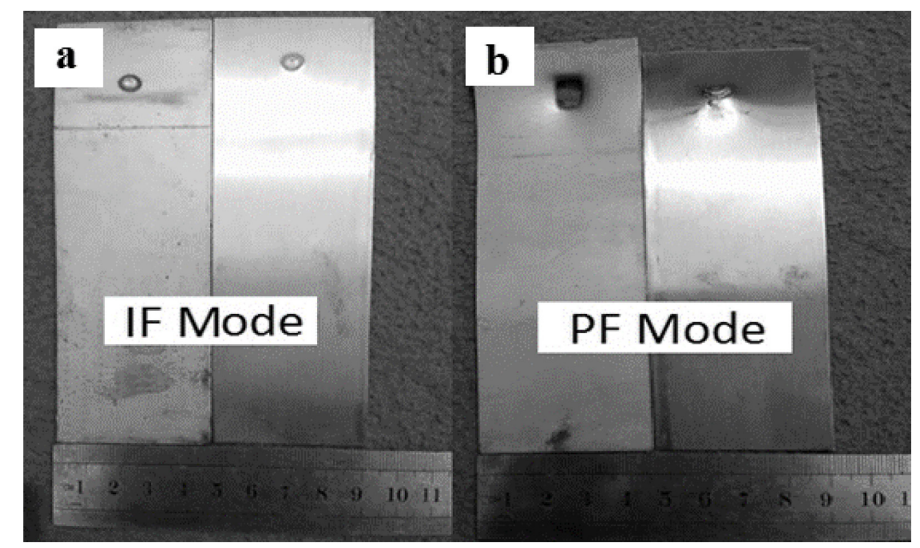

Fig. 7. (a) Interfacial Mode (b) nugget pull-out mode.

It was also noted that the load carrying capacity of the spot welds increased with the increased welding current, which can be seen in Fig. 8.

This happens because of increase in size of the (FZS) as it is evident that the FZS is an important physical aspect in controlling the failure mode of resistance spot welding. FZS increases as the welding current increases because of more generation of heat at the interfaces of the two sheets. It is quite evident after the tensile-shear test that the overload failure mode of the spot welds at low welding current $(>8 \mathrm{kA})$ was interfacial fracture but as soon as the current is increased and subsequently FZS is also increased, overload failure mode changes from interfacial fracture to nugget pull-out mode. It is found out during the investigation that a critical fusion zone size and a minimum current of $8 \mathrm{kA}$ is required to guaranty pull-out failure mode. There is a requirement of a minimum fusion zone size beyond which the spot is inclined towards the pull-out failure mode and under that minimum fusion zone size; the spot is inclined towards interfacial failure mode. The occurrence of failure is always in the mode which requires lesser force. The force due to which the failure mode has come out as interfacial is the shear force acting at the interface of the two sheets and tensile stress is responsible for the nugget pull-out failure mode acting on the weld nugget. 


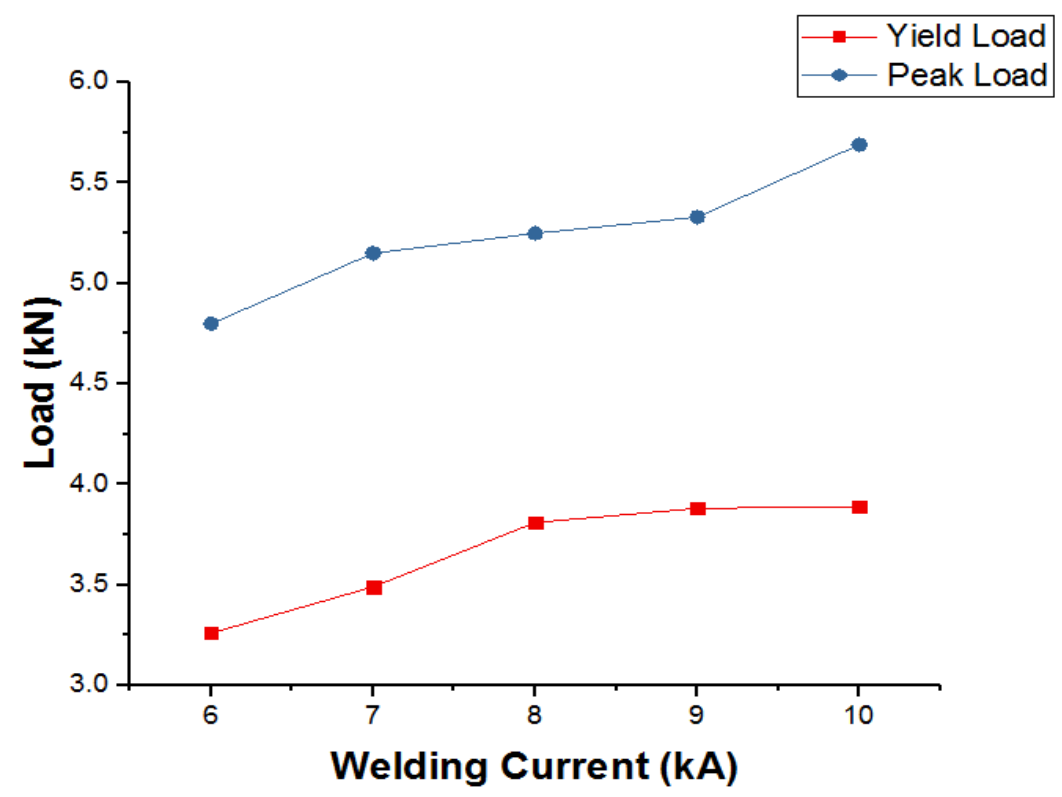

Table 2. Dilution at varying welding current.

\begin{tabular}{|c|c|}
\hline $\begin{array}{c}\text { Welding } \\
\text { Current (kA) }\end{array}$ & Dilution (\%) \\
\hline 6 & 22 \\
\hline 7 & 26 \\
\hline 8 & 49 \\
\hline 9 & 56 \\
\hline 10 & 62 \\
\hline
\end{tabular}

Fig. 8. Yield load and Peak load on varying welding current.

There is always a minimum value of every driving force and when the minimum value of the driving force is reached, the failure occurs in the mode whose critical value has been reached sooner. The factor which leads stress distribution is the FZS. The critical value of shear stress reached earlier then the critical value of tensile stress for small weld nuggets $(>8 \mathrm{kA})$, the failure mode was interfacial else wise the material will fail in nugget pull-out mode. This leads to the existence of a minimum fusion zone size ahead of which the material will fail in pull-out mode and beyond which in Interfacial mode [9].

As it is mentioned above that tensile stress is the driving force for pull-out nugget failure. The stresses bear by the circumference of weld nugget and by the interface of the sheet is explained in the Fig. 7.

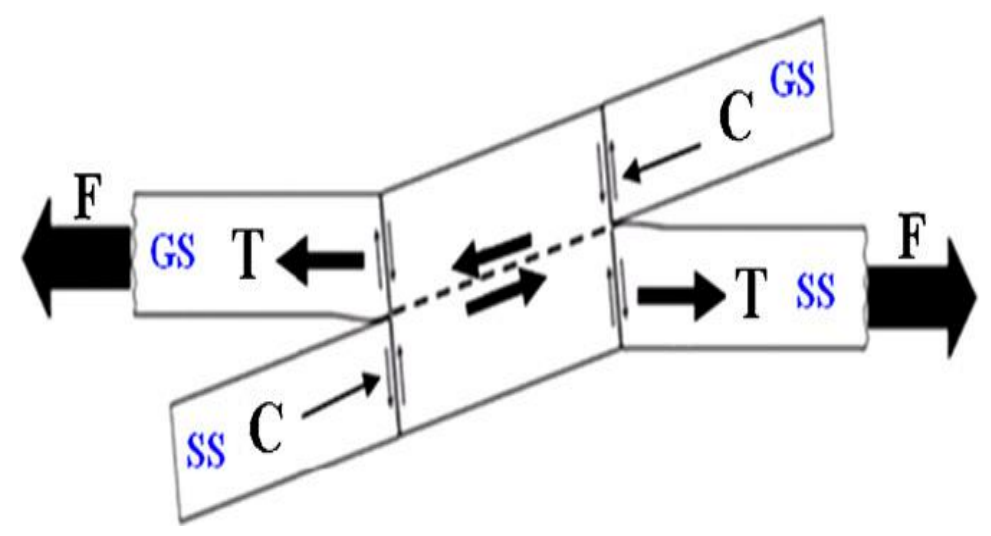

Fig. 9. Schematic diagram showing stress distribution in the sample [3].

The bending moment which is produced because of the overlapping of the two metal sheets induces the tensile stress and weld nugget begin to rotate during the test. The bending stresses are in fact an important factor responsible for nugget pull-out mode. The normal stresses in $\mathrm{C}$ sites are compressive and $\mathrm{T}$ sites are tensile. In the direction of thickness, the increased tensile stress in $\mathrm{T}$ sites causes localized plastic deformation. The competition between the necking of both sheets determines the failure location of nugget pull-out. The legs of the tensile-shear specimen are subjected to tensile stress and due to lower hardness and tensile strength of galvanised steel as compared to stainless steel, the weld nugget pulled out from the galvanised steel due to necking. The initiation of the failure which appears to begin at the circumference of the nugget of galvanised steel sheet is then propagated by the necking. It is now evident from that nugget pull-out failure mode is governed by the size and strength of fusion zone of galvanised steel side [10]. 


\section{Conclusions}

The main objective of this research was to find out the optimum welding parameters at which the weld joint offers best properties. It is found during the study that the most critical factors are welding current, FZS and failure mode that guarantees the spot welds' quality. Different thermal and electrical efficiencies associated with both the steel sheets results in asymmetrical weld nugget formation. The weld nugget size of stainless steel is greater than that of galvanised steel because the thermal resistivity of stainless steel is more than that of galvanised steel. The diameter of the weld nugget increased on both sides as the current is increased. The load carrying capacity of the welds increased with increasing current. A drastic increase in the weld nugget's hardness (Welding current $\leq 8 \mathrm{kA}$ ) indicates the formation of martesnite which is then confirmed with the help of Schaeffler diagram. The weld nugget tends to fail in two modes. At $I w \leq 7 \mathrm{kA}$ in interfacial failure mode and at $I w \geq 8 \mathrm{kA}$ in nugget pull-out failure mode. The nugget pull-out failure mode is most favourable because of the strength and load carrying capacity of those spot welds. The controlling factor in pull-out failure mode is welding current and FZS of galvanized steel side. Interfacial failure mode has shown no plastic deformation whereas a substantial amount of plastic deformation has been shown by pull-out failure mode.

\section{Acknowledgement}

The authors would like to thank "Specialized Auto Parts" for providing the resistance spot welding facility. We would also like to thank NED University of Engineering \& Technology for providing foundation for this project.

\section{References}

[1] S. Aslanlar, A. Ogur, U. Ozsarac, E. Ilhan, Z. Demir, Effect of welding current on mechanical properties of galvanized chromided steel sheets in electrical resistance spot welding, Mater. Des., 28 (2007) 2-7.

[2] M. Pouranvari, P. Marashi, Resistance Spot Welding of Unequal Thickness Low Carbon Steel Sheets, in: Advanced Materials Research, Trans Tech. Publ., 83 (2010) 1205-1211.

[3] P. Marashi, M. Pouranvari, S. Amirabdollahian, A. Abedi, M. Goodarzi, Microstructure and failure behavior of dissimilar resistance spot welds between low carbon galvanized and austenitic stainless steels, Mater. Sci. Eng. A, 480 (2008) 175-180.

[4] M. Pouranvari, Analysis of fracture mode of galvanized low carbon steel resistance spot welds, Inter. J. Multidisci. Sci. Eng., 2 (2011) 36-40.

[5]M. Pouranvari, Effect of welding current on the mechanical response of resistance spot welds of unequal thickness steel sheets in tensile-shear loading condition, Inter. J. Multidisci. Sci. Eng., 2 (2011) 178-189.

[6] L. Boriwal, R. Sarviya, M. Mahapatra, Failure modes of spot welds in quasi-static tensile-shear loading of coated steel sheets, Mater. Tod.: Proceedings, 4 (2017) 3672-3677.

[7] L. Kolařík, M. Sahul, M. Kolaříková, M. Sahul, M. Turňa, Resistance spot welding of low carbon steel to austenitic CrNi stainless steel, Adv. Mater. Res., 875 (2014) 1499-1502.

[8] P. Marashi, M. Pouranvari, S. Amirabdollahian, A. Abedi, M. Goodarzi, Microstructure and failure behavior of dissimilar resistance spot welds between low carbon galvanized and austenitic stainless steels, Mater. Sci. Eng. A, 480 (2008) 175-180.

[9] R.A. Shawon, Investigation into physical and mechanical properties and failure mode of resistance spot welded dissimilar metal joints, Dissertation - Department of Materials \& Metallurgical Engineering, Bangaladesh University of Engineering \& Technology, (2014).

[10] P.C. Lin, S.-H. Lin, J. Pan, Modeling of failure near spot welds in lap-shear specimens based on a plane stress rigid inclusion analysis, Eng. Frac. Mech., 73 (2006) 2229-2249. 